\title{
1,3-Oxazepane-4,7-Diones Compounds: ${ }^{1} \mathrm{H}$ and ${ }^{13} \mathrm{C}$ NMR High-Resolution Spectroscopy (1D and 2D)
}

\author{
AbdulKarim-Talaq Mohammad, Hasnah Osman, and Guan-Yeow Yeap \\ School of Chemical Sciences, Universiti Sains Malaysia, Minden 11800, Penang, Malaysia \\ Correspondence should be addressed to Hasnah Osman, ohasnah@usm.my
}

Received 10 November 2010; Revised 11 January 2011; Accepted 17 January 2011

Academic Editor: Guang Zhu

Copyright ( $) 2011$ AbdulKarim-Talaq Mohammad et al. This is an open access article distributed under the Creative Commons Attribution License, which permits unrestricted use, distribution, and reproduction in any medium, provided the original work is properly cited.

The complete ${ }^{1} \mathrm{H}$ and ${ }^{13} \mathrm{C}$ NMR assignment of new 1,3-oxazepane-4,7-dione compounds has been obtained using one- and twodimensional NMR techniques including COSY, HMQC, and HMBC experiments. The data deduced from this study show that the alkyl chain and the phenyl ring are in different planes compared to the oxazepine ring.

\section{Introduction}

"Oxazepine" refers to any seven-membered ring containing an oxygen and nitrogen atom. The 1,3-oxazepine is a branch of many types of the heterocyclic oxazepine [1-7]. The core structure of 1,3-oxazepane-4,7diones consists of a sevenmemebred ring along with two carbonyl group. Over the years, the syntheses of oxazepine derivatives have been investigated and documented. The result is important of heterocyclic compounds having significant biological uses [813]. Recently, we prepared a variety of 1,3-oxazepinediones in order to study the spectroscopic and liquid crystal properties [14]. In this paper, we present the structural elucidation by $1 \mathrm{D}$ and 2D NMR experiments of 3-alkyl2-(3-hydroxyphenyl)-1,3-oxazepane-4,7-diones with general formula $\left(\mathrm{HOC}_{6} \mathrm{H}_{4}\right) \mathrm{CONC}_{n} \mathrm{H}_{2 n+1} \mathrm{CH}-\mathrm{CH}(\mathrm{CO})_{2}$ (where $n=$ $2,4,6,8,10,12,14,16$, and 18). Here, the hydroxyphenyl and the terminal alkyl chain are attached to the oxazepane ring.

\section{Experimental}

2.1. Material. The experimental part for the synthesized of 1,3-oxazepane-4,7-dione compounds and recording of CHN, FT-IR, and all proton and carbon NMR spectra have been reported elsewhere [15].
2.2. Physical Measurements. Melting points were recorded by GALLENKAMP digital melting point apparatus. The elemental microanalyses (CHN) were performed using a Perkin Elmer 2400 LS Series CHNS/O analyzer. The NMR spectra were recorded in deuterated methyl sulphoxide (DMSO- $\mathrm{d}_{6}$ ) at $298 \mathrm{~K}$ on a Bruker $400 \mathrm{MHz}$ Ultrashied FT-NMR spectrometer equipped with a $5 \mathrm{~mm} \mathrm{BBI}$ inverse gradient probe. Chemical shifts were referenced to internal tetramethylsilane (TMS). The concentration of solute molecules was $50 \mathrm{mg}$ in $1.0 \mathrm{~mL}$ of $\left(\mathrm{DMSO}-\mathrm{d}_{6}\right)$. Standard Bruker pulse programs [16] were used throughout the entire experiment. The spectroscopic details of NMR are summarized in Table 1.

\section{Results and Discussion}

The data of the ${ }^{1} \mathrm{H}$ and ${ }^{13} \mathrm{C}$ NMR chemical shifts for title compounds in DMSO solution are listed in respective Tables 2 and 3.

3.1. $1 D$ and $2 D^{1} H$ NMR Spectral Assignment. A complete assignment for the title compounds can be given based on the representative compound 18oxa (Figure 1 ). The ${ }^{1} \mathrm{H}$ NMR spectra of 2oxa-180xa shows three different regions of chemical shift. The signals of the aromatic proton, which appear as a doublet in the region of $\delta=7.05-7.14 \mathrm{ppm}$ is assigned to the $\mathrm{H} 4$ proton, while a doublet in the range of 


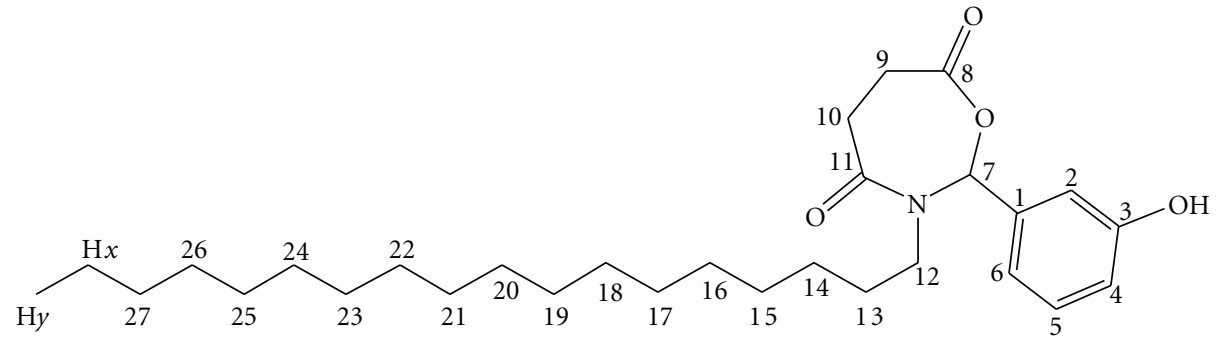

FIGURE 1: Molecular structure with numbering scheme for compound 18oxa.

TABLE 1: Acquisition parameter used in the NMR measurements.

\begin{tabular}{|c|c|c|c|c|c|}
\hline \multirow{2}{*}{ Parameters } & \multicolumn{5}{|c|}{ Experiment } \\
\hline & ${ }^{1} \mathrm{H}$ NMR & ${ }^{13} \mathrm{C}$ NMR & 2D COSY & 2D HMQC & 2D HMBC \\
\hline \multirow[t]{2}{*}{ SF } & $400.1 \mathrm{MHz}$ & $100.6 \mathrm{MHz}$ & $400.1 \mathrm{MHz}$ & $F_{1}=100.6 \mathrm{MHz}$ & $F_{1}=100.61 \mathrm{MHz}$ \\
\hline & & & & $F_{2}=400.1 \mathrm{MHz}$ & $F_{2}=400.1 \mathrm{MHz}$ \\
\hline \multirow[t]{2}{*}{ SW } & $10 \mathrm{ppm}$ & $180 \mathrm{ppm}$ & $10 \mathrm{ppm}$ & $F_{1}=180 \mathrm{ppm}$ & $F_{1}=180 \mathrm{ppm}$ \\
\hline & & & & $F_{2}=10 \mathrm{ppm}$ & $F_{2}=10 \mathrm{ppm}$ \\
\hline PW & $8.3 \mu$ s ( $30^{\circ}$ flip angle $)$ & $20.0 \mu \mathrm{s}\left(90^{\circ}\right.$ flip angle $)$ & $8.3 \mu$ s $\left(90^{\circ}\right.$ flip angle $)$ & $8.3 \mu \mathrm{s}\left(90^{\circ}\right.$ flip angle $)$ & $8.3 \mu \mathrm{s}$ ( $90^{\circ}$ flip angle) \\
\hline AQ & $4.0 \mathrm{~s}$ & $1.3 \mathrm{~s}$ & $0.3 \mathrm{~s}$ & $0.09 \mathrm{~s}$ & $0.4 \mathrm{~s}$ \\
\hline D1 & $1.0 \mathrm{~s}$ & $2.0 \mathrm{~s}$ & $2.0 \mathrm{~s}$ & $1.0 \mathrm{~s}$ & $1.0 \mathrm{~s}$ \\
\hline NS & 16 & 20000 & 16 & 88 & 92 \\
\hline \multirow[t]{2}{*}{$\mathrm{TD}$} & $66 \mathrm{k}$ & $66 \mathrm{k}$ & $F_{1}=256$ & $F_{1}=512$ & $F_{1}=512$ \\
\hline & & & $F_{2}=2048$ & $F_{2}=1024$ & $F_{2}=4096$ \\
\hline
\end{tabular}

Abbreviations: $F_{1},{ }^{13} \mathrm{C}$ Channel (except 2D COSY, where $F_{1}$ and $F_{2}$ are ${ }^{1} \mathrm{H}$ channel); SF. spectrometer frequency; SW, spectral width; AQ, acquisition time; $\mathrm{DI}$, relaxation delay; NS, number; TD, number of data point.

TABLE 2: ${ }^{1} \mathrm{H}$ NMR chemical shifts (ppm) of compounds 2oxa-18oxa.

\begin{tabular}{|c|c|c|c|c|c|c|c|c|c|}
\hline \multirow{2}{*}{ Atom } & \multicolumn{9}{|c|}{ Chemical shift (ppm) } \\
\hline & $20 x a$ & $40 x a$ & $60 \times a$ & $80 \times a$ & $100 x a$ & $120 x a$ & $140 x a$ & $160 \times a$ & $180 x$ \\
\hline $\mathrm{H} 2$ & 7.15 & 7.21 & 7.12 & 7.14 & 7.14 & 7.15 & 7.10 & 7.24 & 7.21 \\
\hline $\mathrm{H} 4$ & 7.10 & 7.13 & 7.14 & 7.11 & 7.09 & 7.05 & 7.10 & 7.11 & 7.08 \\
\hline H5 & 7.41 & 7.45 & 7.38 & 7.38 & 7.39 & 7.25 & 7.24 & 7.36 & 7.38 \\
\hline H6 & 6.67 & 6.64 & 6.68 & 6.74 & 6.70 & 6.82 & 6.81 & 6.92 & 6.94 \\
\hline $\mathrm{H} 7$ & 7.56 & 7.60 & 7.62 & 7.64 & 7.93 & 7.89 & 7.93 & 7.92 & 7.91 \\
\hline $\mathrm{OH}$ & 9.50 & 9.46 & 9.23 & 9.19 & 9.81 & 9.92 & 9.91 & 9.92 & 9.94 \\
\hline $\mathrm{H} 9$ & 2.21 & 2.35 & 2.27 & 2.25 & 2.26 & 2.30 & 2.28 & 2.29 & 2.28 \\
\hline $\mathrm{H} 10$ & 2.40 & 2.42 & 2.41 & 2.43 & 2.45 & 2.48 & 2.40 & 2.42 & 2.41 \\
\hline H12 & 3.12 & 3.22 & 3.10 & 3.13 & 3.21 & 3.01 & 3.03 & 3.01 & 3.05 \\
\hline $\mathrm{H} 13$ & 1.74 & 1.73 & 1.71 & 1.70 & 1.76 & 1.76 & 1.73 & 1.71 & 1.75 \\
\hline H14-H15-27 & & - & 1.30 & 1.25 & 1.24 & 1.25 & 1.24 & 1.23 & 1.23 \\
\hline $\mathrm{H} x$ & & 1.28 & 1.32 & 1.31 & 1.27 & 1.29 & 1.29 & 1.30 & 1.28 \\
\hline $\mathrm{H} y$ & & 0.94 & 0.86 & 0.87 & 0.88 & 0.85 & 0.85 & 0.85 & 0.86 \\
\hline
\end{tabular}

$\delta=6.64-6.94 \mathrm{ppm}$ attributed to H6. The singlet in the region of $\delta=7.10-7.24 \mathrm{ppm}$ is due to the $\mathrm{H} 2$ proton. The triplet in the region $\delta=7.24-7.45 \mathrm{ppm}$ can be ascribed to the H5 proton. The protons $(\mathrm{H} 2, \mathrm{H} 4, \mathrm{H} 5$, and $\mathrm{H} 6)$ are found to be nonequivalent. The hydroxyl proton appears as a singlet at $\delta=9.19-9.94 \mathrm{ppm} .{ }^{1} \mathrm{H}$ NMR spectra of all these compounds show two two-proton triplets in the high field region of about $\delta=2.21-2.35 \mathrm{ppm}$ and $2.40-2.48 \mathrm{ppm}$ due to the heterocyclic ring protons $\mathrm{H} 9$ and $\mathrm{H} 10$, respectively. The chemical shift of the $\mathrm{H} 7$ proton is a singlet in the range of $\delta=7.56-7.93 \mathrm{ppm}$. The alkyl group shows four signals and a quintet in the range of $\delta=1.71-1.76 \mathrm{ppm}$. This quintet is attributed to the H13. 


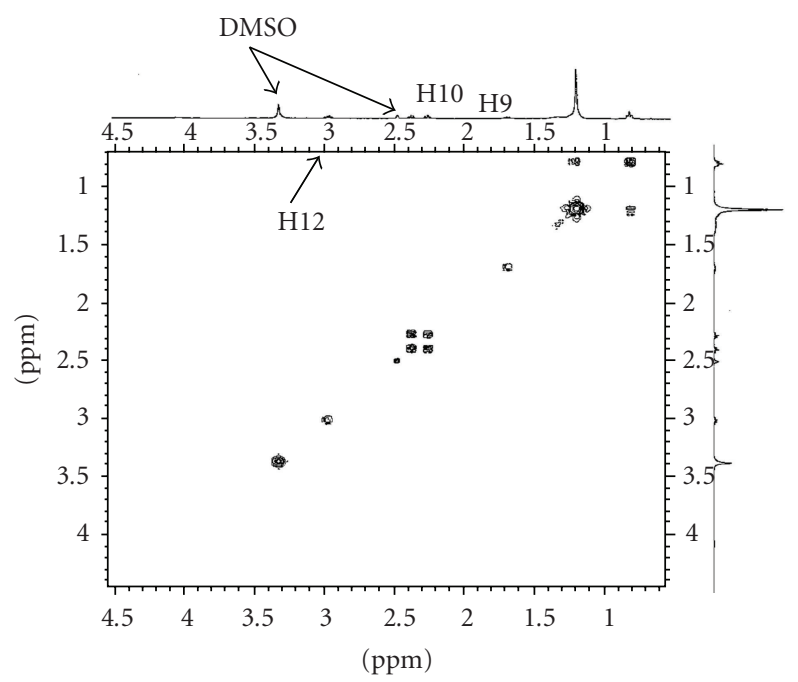

(a)

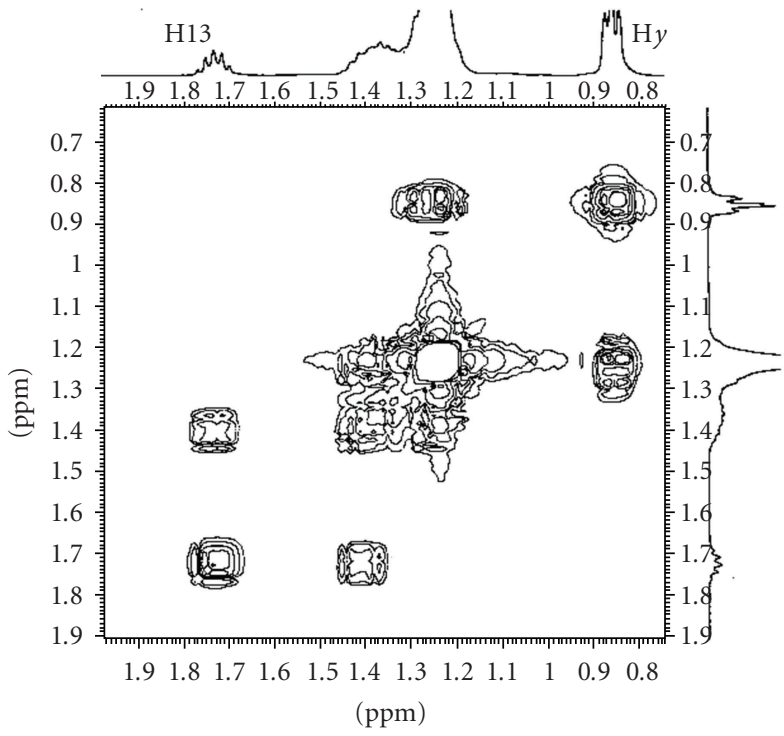

(c)

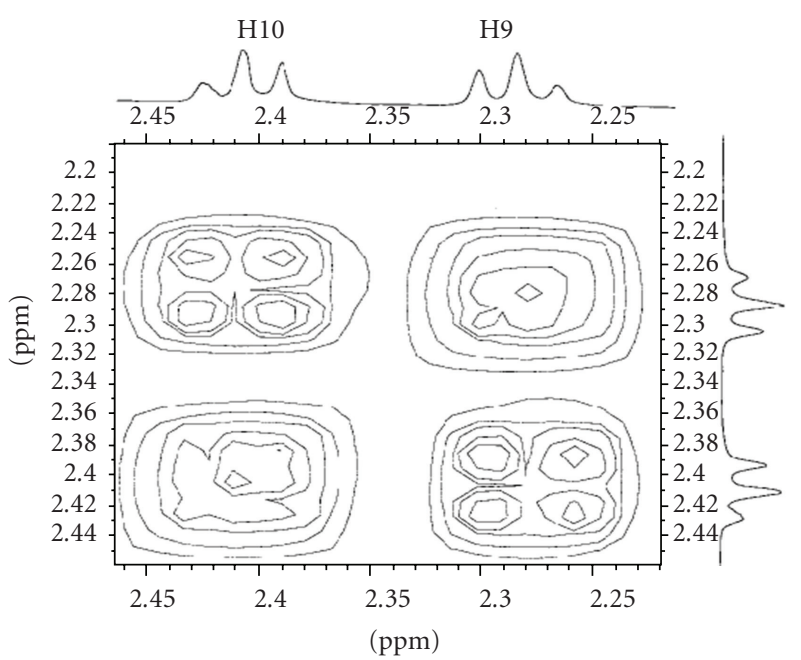

(b)

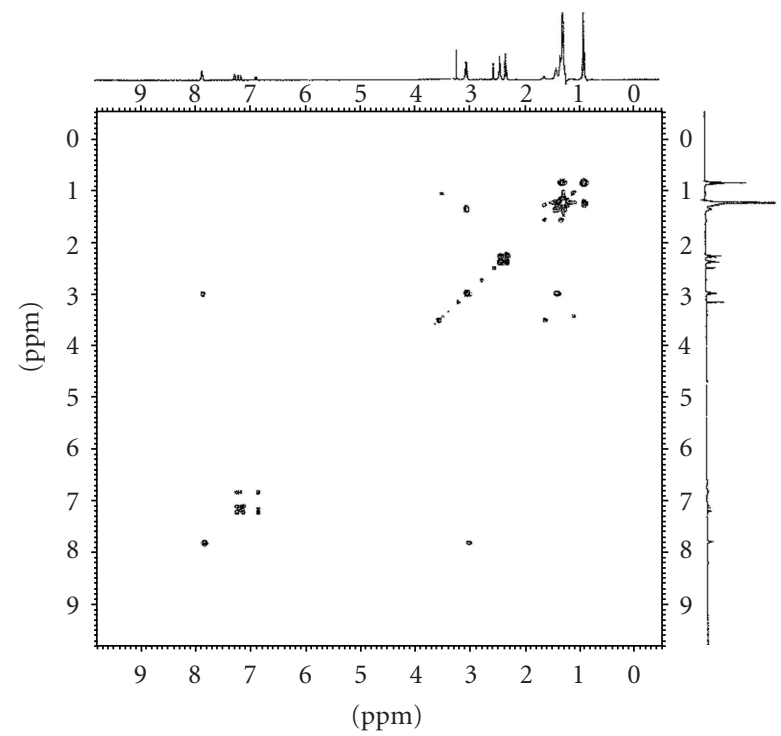

(d)

FIGURE 2: ${ }^{1} \mathrm{H}-{ }^{1} \mathrm{H}$ connectiveities in the COSY spectra with select relationship for compound 6oxa. (a) Expansion of aliphatic and hetero cyclic proton spectrum. (b) Expansion of heterocyclic proton spectrum. (c) Expansion of aliphatic proton region. (d) full ${ }^{1} \mathrm{H}-{ }^{1} \mathrm{H}$ COSY spectrum.

The two triplets in the range of $\delta=0.85-0.94 \mathrm{ppm}$ and $\delta=$ 3.01-3.22 ppm can be assigned to the methyl protons $(\mathrm{H} y)$ and the methylene protons (H12), respectively. The signals of the alkyl protons from $\mathrm{H} 14$ to $\mathrm{H} 27$ are confirmed by multiplets in the range of $\delta=1.23-1.30 \mathrm{ppm}$.

The assignments of the ${ }^{1} \mathrm{H}$ NMR spectra of these compounds were aided by 2D COSY experiments. The COSY experiments further substantiated the correlation between the equivalent proton pairs with the adjacent protons, wherein the cross peak resulting from these correlations appear at the same region. A typical COSY spectrum of the ${ }^{1} \mathrm{H}-{ }^{1} \mathrm{H}$ connectivities in 6oxa is shown in Figure 2. At the upper field, H9 in heterocyclic ring correlated with the proton $\mathrm{H} 10$ in the same ring observed as triplets at $\delta=2.27$ and $2.41 \mathrm{ppm}$, respectively. The quintet at $\delta=1.71 \mathrm{ppm}$ is assigned to $\mathrm{H} 13$ proton which correlated with the multiplets at $\delta=1.30 \mathrm{ppm}$. A similar phenomenon can also be found for $\mathrm{H} x$ at $\delta=1.32 \mathrm{ppm}$ which correlated with $\mathrm{H} y$ at $\delta=$ $0.86 \mathrm{ppm}$. However, the $\mathrm{H} 14$ to $\mathrm{H} 27$ protons for compounds (80xa to 180xa) exhibit complexity which cannot be resolved using homonuclear decoupling. The COSY correlation also reveals that the NMR signal of proton $\mathrm{H} 5$ at $\delta=7.38 \mathrm{ppm}$ had correlated with the NMR signal of aromatic protons H4 $(\delta=$ $7.14)$ and H6 $(\delta=6.68)$ ppm, respectively. In the same way, the aromatic proton $(\mathrm{H} 2)$ in the region of $\delta=7.12 \mathrm{ppm}$ was found to be not correlated with any other aromatic protons. However, COSY data also reveals that the $(\mathrm{OH})$ proton at $\delta=9.23 \mathrm{ppm}$ was found to be correlated with the signal assigned to the singlet in the region of $\delta=7.12 \mathrm{ppm}$ but not with doublet assigned at $\delta=7.14 \mathrm{ppm}(\mathrm{H} 4)$. This result 


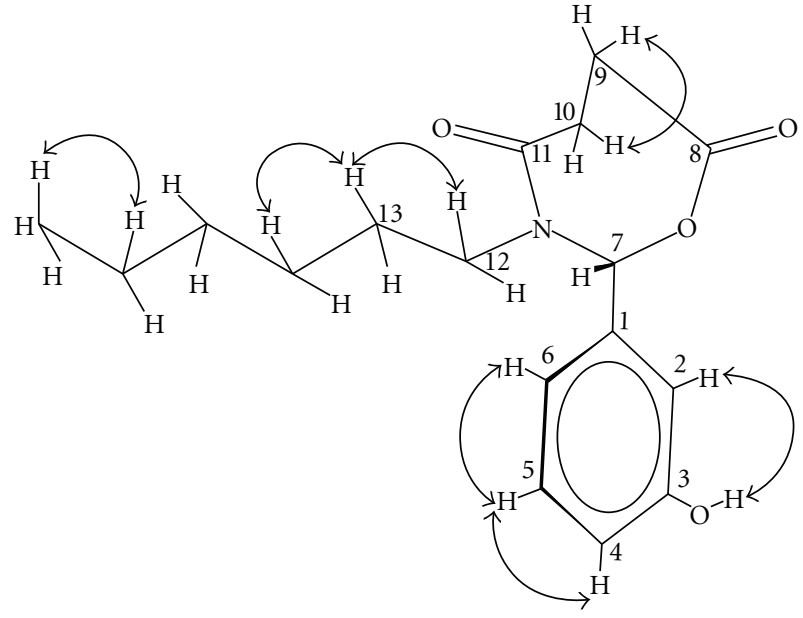

Figure $3:{ }^{1} \mathrm{H}-{ }^{1} \mathrm{H}$ connectiveities in the COSY, select relationship for compound 6oxa.

helps to show the hydrogen atom of the hydroxyl group is not coplanar with the phenyl ring. Select relationship for compound 6oxa was shown in Figure 3.

3.2. ${ }^{13} \mathrm{C} N M R$ and $2 D$ Spectral Assignment. Compounds 2oxa-18oxa were also characterized by ${ }^{13} \mathrm{C}$ NMR and DEPT135 for the protonated carbons which are governed by the additive rules and substitution effect. The ${ }^{13} \mathrm{C}$ NMR spectra of these compounds were all similar. Two downfield signals observed at $\delta=171.54-172.35 \mathrm{ppm}$ and $\delta=174.64$ $176.70 \mathrm{ppm}$ are attributed to the carbonyl carbons (C8 and C11) of the seven-membered ring. However, the highfield signal in the region of $\delta=13.80-15.03 \mathrm{ppm}$ is assigned for Cy of the methyl in the alkyl chain. The signals in the range of $\delta=39.36-40.15 \mathrm{ppm}, 29.60-30.85 \mathrm{ppm}, 26.40-34.93 \mathrm{ppm}$, and $22.50-23.12 \mathrm{ppm}$ are attributed to the respective C12, $\mathrm{C} 13, \mathrm{C} 14$ to $\mathrm{C} 25$, and $\mathrm{C} x$ in the aliphatic chain. In addition to the aliphatic carbons, the signal for $\mathrm{C} 9$ and $\mathrm{C} 10$ of the seven-membered ring appear in the range of $\delta=27.20$ $28.80 \mathrm{ppm}$ and $\delta=29.50-29.98 \mathrm{ppm}$, respectively. The signal in the region of $\delta=67.56-70.58 \mathrm{ppm}$ is attributed to C7. The resonance due to the aromatic carbon at $\delta=137.16-$ $138.74,114.10-115.80,119.42-122.49,130.18-132.66$, and $121.12-123.05 \mathrm{ppm}$ are assigned to $\mathrm{C} 1, \mathrm{C} 2, \mathrm{C} 4, \mathrm{C} 5$, and C6. The ${ }^{13} \mathrm{C}$ NMR signal for C3 $(\delta=158.43-161.06 \mathrm{ppm})$ showed comparatively downfield shift as compared to the other phenyl carbons in all the title compounds due to adjacent to hydroxyl group. The only difference observed was the increase in the number of aliphatic carbon signals by two each time when compound 2oxa to 180xa was analyzed.

The HMQC spectra of all the compounds were recorded, and the chemical shifts are assigned. The HMQC spectra provide information regarding the through bond connection between the protons and the carbon atoms to which they are directly attached. The data of compound 18oxa are discussed as an example. The HMQC experiment enabled the assignment of the one-bond connectivity in the proton singlet at $\delta=7.21 \mathrm{ppm}$, which correlated with carbon signal at $\delta=115.54 \mathrm{ppm}$, a doublet at $\delta=7.08 \mathrm{ppm}$ with the methine at $\delta=121.91 \mathrm{ppm}$, the triplet at $\delta=7.38 \mathrm{ppm}$ with the signal at $\delta=131.13 \mathrm{ppm}$, and the doublet at $\delta=$ $6.94 \mathrm{ppm}$ shows the correlation with the signal at $\delta=122.65$. The signals were observed at $\delta=27.23 \mathrm{ppm}$ and $29.51 \mathrm{ppm}$ which are assigned to carbon atoms in the heterocyclic ring (C9 and C10) due to its interaction with proton resonances at $\delta=2.28 \mathrm{ppm}$ and $2.41 \mathrm{ppm}$. The proton singlet for $\mathrm{H} 7$ at $\delta=7.91 \mathrm{ppm}$ is correlated with the carbon signal $\delta=$ $69.21 \mathrm{ppm}$. At upper field, we were able to assign the three proton triplet at $\delta=0.86 \mathrm{ppm}$ which correlated with the carbon signal at $\delta=14.89 \mathrm{ppm}$, and also a signal at $\delta=$ $1.28 \mathrm{ppm}$ correlated with the carbon signal at $\delta=22.90 \mathrm{ppm}$. In the same way, the multiplets of the aliphatic proton signal at $\delta=1.23 \mathrm{ppm}$ is correlated with the carbon signals at $\delta=$ $27.80 \mathrm{ppm}$ to $33.87 \mathrm{ppm}$.

As for the HMBC spectra, the assignment for the carbon nuclei can also be supported by long-range connectivities. The HMBC spectra of compounds help to observe the correlation of aromatic quaternary carbon and its neighboring proton. In addition, the HMBC experiment allowed the assignment of the aromatic nonprotonated and protonated carbons. For example, in 16oxa Figure 4, the proton singlet at $\delta=7.24 \mathrm{ppm}$ correlated through ${ }^{2} \mathrm{~J}$ bond with the aromatic carbons at $\delta=137.16$ and $158.82 \mathrm{ppm}$, respectively, and with the aromatic carbon at $\delta=122.95 \mathrm{ppm}$ via ${ }^{3} \mathrm{~J}$, while it also correlated with the aromatic carbon at $\delta=132.66 \mathrm{ppm}$ through ${ }^{4} \mathrm{~J}$. Finally, the long-range connectivities through intramolecular interaction (intra J) of this proton correlate with the carbon at $\delta=39.90 \mathrm{ppm}$. Likewise, the doublet at $\delta=7.11 \mathrm{ppm}$ which was assigned to the $\mathrm{H} 4$ proton is correlated through ${ }^{2} \mathrm{~J},{ }^{3} \mathrm{~J}$, and ${ }^{4} \mathrm{~J}$ with the respective aromatic carbons at $\delta=132.66 \mathrm{ppm}, 122.95 \mathrm{ppm}$, and $137.16 \mathrm{ppm}$. The one proton doublet at $\delta=6.92 \mathrm{ppm}$ was also shown to be correlated with the carbons at $\delta=132.66 \mathrm{ppm}, 120.49 \mathrm{ppm}$, $69.86 \mathrm{ppm}$, and $158.82 \mathrm{ppm}$ through the long-range connectivities via ${ }^{2} \mathrm{~J},{ }^{3} \mathrm{~J}$, and ${ }^{4} \mathrm{~J}$, respectively. The aromatic proton, observed as a triplet at $\delta=7.36 \mathrm{ppm}$ was correlated with the aromatic carbons at $\delta=120.49,122.95 \mathrm{ppm}$, $137.16 \mathrm{ppm}$, and $115.49 \mathrm{ppm}$ through the respective longrange connectivities of ${ }^{2} \mathrm{~J},{ }^{3} \mathrm{~J}$, and ${ }^{4} \mathrm{~J}$. The spectrum also allowed the assignment of the protons of the heterocyclic ring which was observed as a triplet at $\delta=2.29 \mathrm{ppm}$ which correlated with the carbonyl carbon at $\delta=171.56 \mathrm{ppm}$ and with the carbon at $\delta=29.56 \mathrm{ppm}$ through the long-range connectivity ${ }^{2} \mathrm{~J}$. It also correlated with the carbon signal at $\delta$ $=174.71$ through the long range connectivity ${ }^{3} \mathrm{~J}$. In the same way the triplet of the seven-membered ring at $\delta=2.42 \mathrm{ppm}$, is correlated with the carbon at $\delta=27.25 \mathrm{ppm}$ and the carbonyl carbon at $\delta=174.71 \mathrm{ppm}$ through ${ }^{2}$ J. Furthermore, the singlet at $\delta=7.92 \mathrm{ppm}$ which was assigned for proton $\mathrm{H} 7$ was observed to correlate with the aromatic carbon at $\delta=$ $137.16 \mathrm{ppm}$ through ${ }^{2} \mathrm{~J}$, with the carbons at $\delta=171.56 \mathrm{ppm}$ and $39.90 \mathrm{ppm}$ through ${ }^{3} \mathrm{~J}$, and finally with the carbon at $\delta=$ $29.96 \mathrm{ppm}$ through the long-range connectivity ${ }^{4} \mathrm{~J}$.

The aliphatic chain protons is assigned from the triplet at $\delta=3.01 \mathrm{ppm}$ which correlated with carbon at $\delta=$ 29.96 through ${ }^{2} \mathrm{~J}$, with carbons at $\delta=69.86$ and $27.44 \mathrm{ppm}$ through ${ }^{3} \mathrm{~J}$, and with the aromatic carbon at $\delta=137.16 \mathrm{ppm}$ 


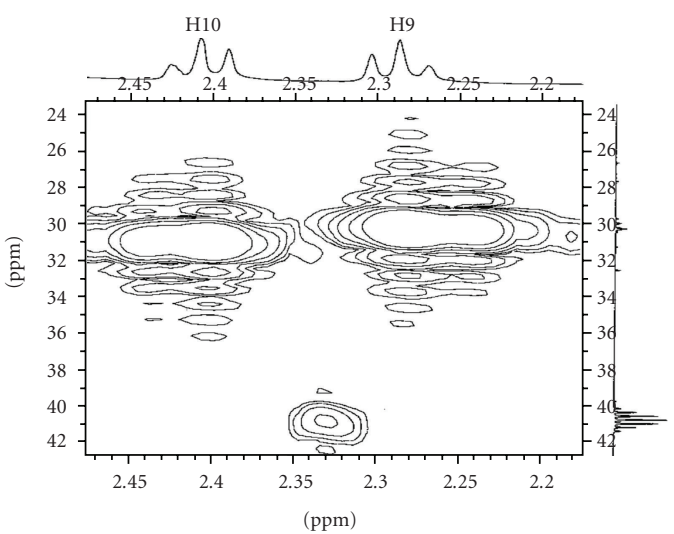

(a)

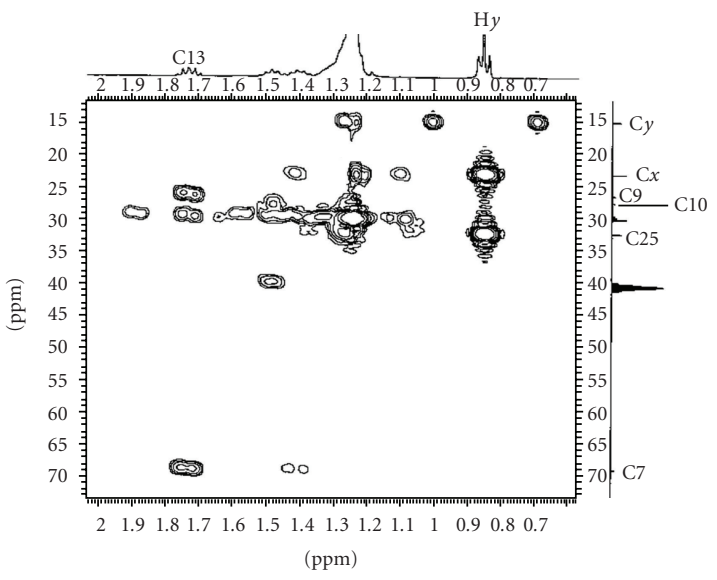

(c)

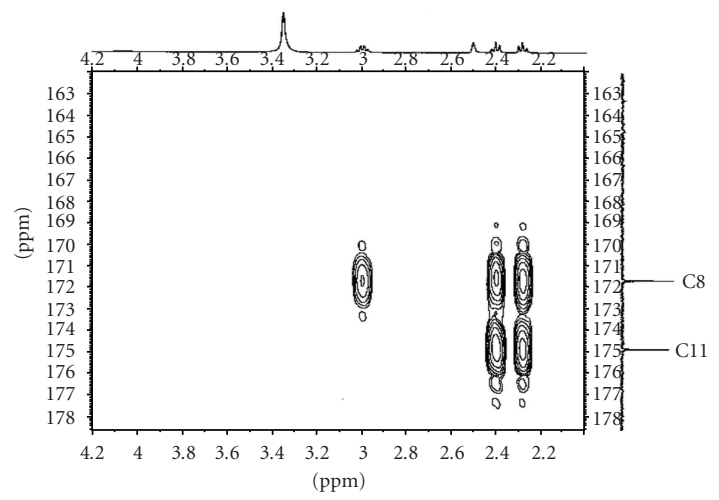

(b)

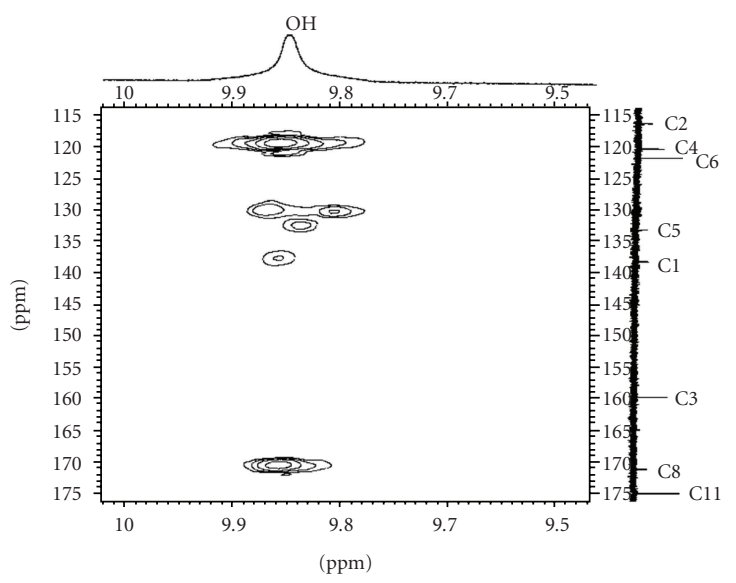

(d)

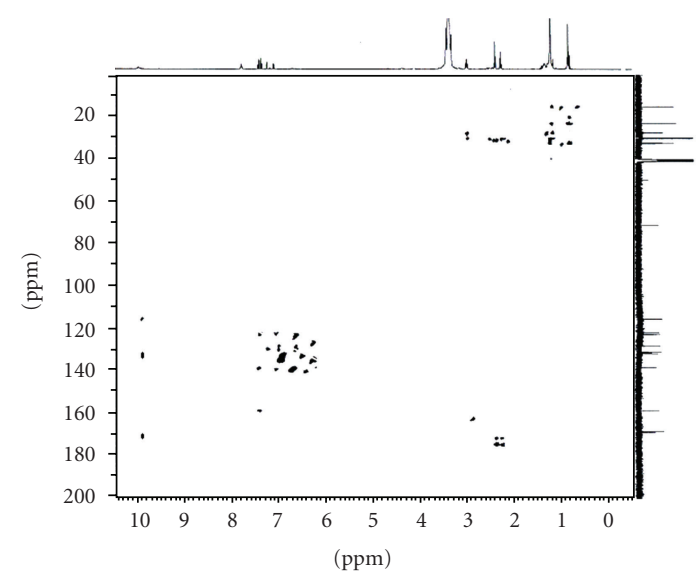

(e)

Figure 4: Long range C-H correlations in the HMBC spectra of compound 16oxa. From (a) to (d) Expansion of aliphatic and hetero cyclic proton spectra. (e) HMBC spectrum of 16oxa.

through ${ }^{4} \mathrm{~J}$. It also correlated with the aromatic carbon at $\delta$ $=122.95 \mathrm{ppm}$ and the carbonyl carbon which was located at $\delta=171.56 \mathrm{ppm}$ through long-range connectivities (intra J). Additional correlation for the aliphatic protons were detected from the observed triplet at $\delta=0.85 \mathrm{ppm}$ which was assigned to the $\mathrm{H} y$ protons with the carbon at $\delta=22.95 \mathrm{ppm}$, with the carbon at $\delta=33.57 \mathrm{ppm}$, and with carbon at $\delta=31.19 \mathrm{ppm}$ in the respective, long-range connectivities
${ }^{2} \mathrm{~J},{ }^{3} \mathrm{~J}$, and ${ }^{4} \mathrm{~J}$. These data help to confirm the correlation between the proton signal at $\delta=1.30 \mathrm{ppm}$ with the carbon signals at $\delta=14.76 \mathrm{ppm}$ and $33.57 \mathrm{ppm}, 31.19 \mathrm{ppm}$ and $31.30 \mathrm{ppm}$ through the long-range connectivities ${ }^{2} \mathrm{~J},{ }^{3} \mathrm{~J}$, and ${ }^{4}$ J, respectively.

Selected intramolecular through bond connectivities from HMBC spectrum for compound 16oxa is shown in Figure 5. 


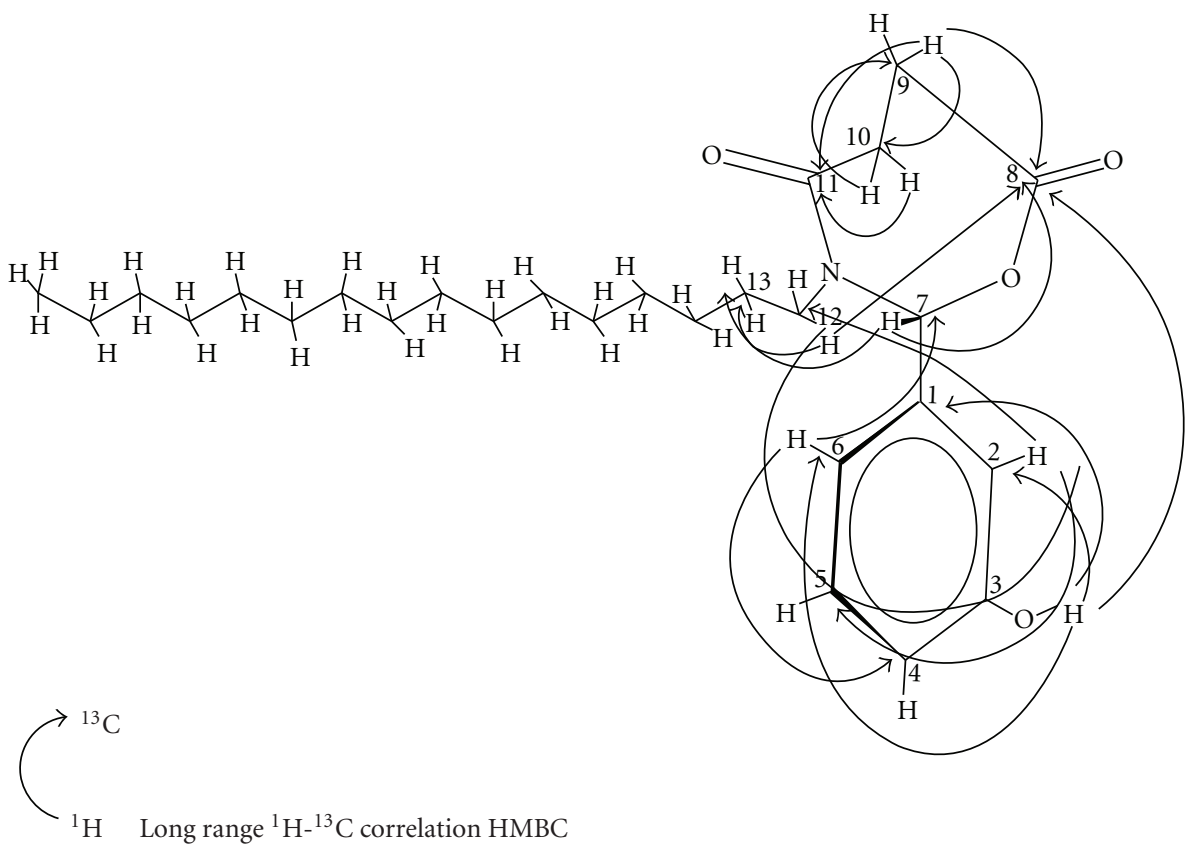

Figure 5: ${ }^{1} \mathrm{H}_{-}{ }^{13} \mathrm{C}$ correlation $\mathrm{HMBC}$, select intramolecular interaction for $\mathbf{1 6 0 x a}$.

TABle 3: ${ }^{13} \mathrm{C}$ NMR and DEPT135 chemical shifts (ppm) of compounds 2oxa-18oxa.

\begin{tabular}{|c|c|c|c|c|c|c|c|c|c|}
\hline \multirow{2}{*}{ Carbon no. } & \multicolumn{9}{|c|}{ Chemical shift (ppm) } \\
\hline & 2oxa & $40 x a$ & $60 \times a$ & $80 \times a$ & $10 \mathrm{oxa}$ & $120 x a$ & $140 x a$ & $160 x a$ & $180 x$ \\
\hline 1 & 137.22 & 138.10 & 138.10 & 138.50 & 138.65 & 138.49 & 138.74 & 137.16 & 138.13 \\
\hline 2 & 114.10 & 114.95 & 115.80 & 115.50 & 115.01 & 114.48 & 115.08 & 115.49 & 115.54 \\
\hline 3 & 158.43 & 158.72 & 161.06 & 158.85 & 158.65 & 158.83 & 158.88 & 158.82 & 158.83 \\
\hline 4 & 119.42 & 120.43 & 122.40 & 121.90 & 121.01 & 122.49 & 121.18 & 120.49 & 121.91 \\
\hline 5 & 130.45 & 131.53 & 130.40 & 132.36 & 130.18 & 130.42 & 131.18 & 132.66 & 131.13 \\
\hline 6 & 121.23 & 121.35 & 122.60 & 122.63 & 121.12 & 123.05 & 122.62 & 122.95 & 122.65 \\
\hline 7 & 70.58 & 70.50 & 70.03 & 67.56 & 67.92 & 68.34 & 68.62 & 69.86 & 69.21 \\
\hline 8 & 172.35 & 172.05 & 172.12 & 171.54 & 172.05 & 171.58 & 171.92 & 171.56 & 171.57 \\
\hline 9 & 28.58 & 28.80 & 27.20 & 28.08 & 27.70 & 27.62 & 27.27 & 27.25 & 27.23 \\
\hline 10 & 29.50 & 29.50 & 29.70 & 29.98 & 29.81 & 29.52 & 29.53 & 29.56 & 29.51 \\
\hline 11 & 175.64 & 176.32 & 176.70 & 174.71 & 175.54 & 174.73 & 174.64 & 174.71 & 174.64 \\
\hline 12 & 40.15 & 40.15 & 40.03 & 40.06 & 39.80 & 39.36 & 39.83 & 39.90 & 39.85 \\
\hline 13 & 30.41 & 30.51 & 30.30 & 30.85 & 30.03 & 29.67 & 29.60 & 29.96 & 29.95 \\
\hline 14 & & & 27.12 & 27.77 & 27.65 & 27.80 & 26.40 & 27.44 & 27.80 \\
\hline 15 & & & 34.40 & 29.60 & 29.48 & 29.89 & 29.90 & 29.88 & 30.62 \\
\hline 16 & & & & 31.37 & 29.56 & 29.78 & 29.83 & 29.76 & 29.57 \\
\hline 17 & & & & 34.93 & 31.70 & 29.60 & 29.70 & 29.70 & 29.50 \\
\hline 18 & & & & & 31.10 & 29.58 & 29.63 & 29.64 & 29.47 \\
\hline 19 & & & & & 34.70 & 31.40 & 29.59 & 29.57 & 29.42 \\
\hline 20 & & & & & & 31.10 & 29.50 & 29.50 & 29.38 \\
\hline 21 & & & & & & 34.60 & 31.46 & 31.48 & 29.30 \\
\hline 22 & & & & & & & 31.12 & 31.40 & 29.29 \\
\hline 23 & & & & & & & 32.50 & 31.30 & 29.15 \\
\hline 24 & & & & & & & & 31.19 & 29.07 \\
\hline 25 & & & & & & & & 33.57 & 28.78 \\
\hline 26 & & & & & & & & & 31.17 \\
\hline 27 & & & & & & & & & 33.87 \\
\hline$X$ & & 22.50 & 22.80 & 23.12 & 22.94 & 22.53 & 22.91 & 22.95 & 22.90 \\
\hline$y$ & & 13.80 & 14.04 & 15.01 & 15.03 & 15.00 & 14.82 & 14.76 & 14.89 \\
\hline
\end{tabular}




\section{Conclusions}

In this paper, we present some new heterocyclic compounds with 1,3-oxazepane cores. The detail NMR assignments of these compounds have been discussed by ${ }^{1} \mathrm{H},{ }^{13} \mathrm{C} \mathrm{NMR}$, and DEPT135 spectra along with two-dimensional COSY, ${ }^{1} \mathrm{H}$ ${ }^{13} \mathrm{C}$ HMQC, and HMBC spectra. Synthesis results of this work could be useful for other chemists working on the field of heterocyclic oxazepine.

\section{Acknowledgments}

The authors thank the Universiti Sains Malaysia and the Malaysian Government for financing this project through RU Grant no. 1001/PKIMIA/811133 and USM-RU-PRGS Grant No. 1001/PKIMIA/842022.

\section{References}

[1] A. Al-Harrasi and H. U. Reissig, "Ring enlargement of enantiopure 1,2-oxazines to 1,2-oxazepine derivatives and their palladium-catalyzed couplings," Synlett, no. 15, pp. 23762378, 2005.

[2] E. S. Kumar and D. N. Dhar, "A simple route for the synthesis of oxazepine-2-one systems using chlorosulfonyl isocyanate," Synthetic Communications, vol. 25, no. 13, pp. 1939-1945, 1995.

[3] J. P. Praly, C. D. Stèfano, and L. A. Somsák, "Photolysis of glycopyranosyl azides C-1 substituted by cyano-, amido-, or tetrazolyl-groups," Tetrahedron Asymmetry, vol. 11, no. 2, pp. 533-537, 2000.

[4] J. P. Wolfe, R. A. Rennels, and S. L. Buchwald, "Intramolecular palladium-catalyzed aryl amination and aryl amidation," Tetrahedron, vol. 52, no. 21, pp. 7525-7546, 1996.

[5] C. Ma, S. J. Liu, L. Xin, J. R. Falck, and D. S. Shin, "Novel formation of 1,3-oxazepine heterocycles via palladium-catalyzed intramolecular coupling reaction," Tetrahedron, vol. 62, no. 38, pp. 9002-9009, 2006.

[6] A. A. Abdel-Hafez and B. A. Abdel-Wahab, "5-(4chlorophenyl)-5,6-dihydro-1,3-oxazepin-7(4H)-one derivatives as lipophilic cyclic analogues of baclofen: design, synthesis, and neuropharmacological evaluation," Bioorganic and Medicinal Chemistry, vol. 16, no. 17, pp. 7983-7991, 2008.

[7] Y. Tang, J. C. Fettinger, and J. T. Shaw, "One-step synthesis of complex nitrogen heterocycles from lmines and alkylsubstituted maleic anhydrides," Organic Letters, vol. 11, no. 17, pp. 3802-3805, 2009.

[8] C. L. Allaway, M. Daly, M. Nieuwenhuyzen, and G. C. Saunders, "Synthesis of polyfluorodibenz $[b, f][1,4]$ oxazepines by the cyclization of 2-[(polyfluorobenzylidene)amino]phenols," Journal of Fluorine Chemistry, vol. 115, no. 1, pp. 91-99, 2002.

[9] B. Doherty, M. Nieuwenhuyzen, G. C. Saunders, and M. S. Sloan, "Functionalized fluorinated arylethers by ring-opening of 1,2,3,4-tetrafluorodibenz $[b, f][1,4]$ oxazepine," Journal of Fluorine Chemistry, vol. 119, no. 1, pp. 15-19, 2003.

[10] A. Kamal, V. Tekumalla, P. Raju, V. G. M. Naidu, P. V. Diwan, and R. Sistla, "Pyrrolo[2,1-c][1,4]benzodiazepine- $\beta$ glucuronide prodrugs with a potential for selective therapy of solid tumors by PMT and ADEPT strategies," Bioorganic and Medicinal Chemistry Letters, vol. 18, no. 13, pp. 3769-3773, 2008.
[11] K. Bajaj, Archana, and A. Kumar, "Synthesis and pharmacological evaluation of newer substituted benzoxazepine derivatives as potent anticonvulsant agents," European Journal of Medicinal Chemistry, vol. 39, no. 4, pp. 369-376, 2004.

[12] M. T. Crimmins and A. L. Choy, "An asymmetric aldolring-closing metathesis strategy for the enantioselective construction of oxygen heterocycles: an efficient approach to the enantioselective synthesis of (+)-laurencin," Journal of the American Chemical Society, vol. 121, no. 24, pp. 5653-5660, 1999.

[13] J. Taunton, J. L. Collins, and S. L. Schreiber, "Synthesis of natural and modified trapoxins, useful reagents for exploring histone deacetylase function," Journal of the American Chemical Society, vol. 118, no. 43, pp. 10412-10422, 1996.

[14] G. Y. Yeap, A. T. Mohammad, and H. Osman, "Synthesis, spectroscopic and mesomorphic studies on heterocyclic liquid crystals with 1,3-oxazepine-4,7-dione, 1,3-oxazepane-4,7dione and 1,3-oxazepine-1,5-dione cores," Journal of Molecular Structure, vol. 982, no. 1-3, pp. 33-44, 2010.

[15] A. T. Mohammad, H. Osman, and G. Y. Yeap, "Synthesis of new 1,3-oxazepane-4,7diones," submitted to Journal of Synthetic Communications.

[16] Bruker program 1D WIN-NMR (release 6.0) and 2D WINNMR (release 6.1). 


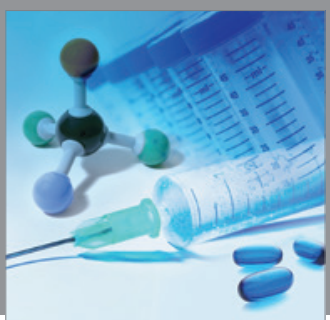

International Journal of

Medicinal Chemistry

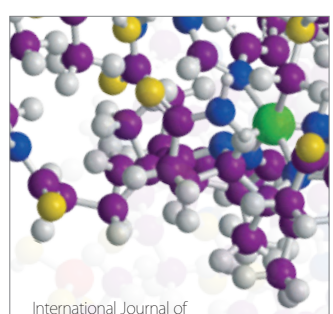

Carbohydrate Chemistry

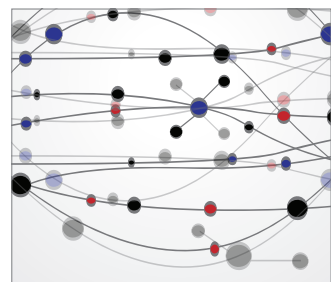

The Scientific World Journal
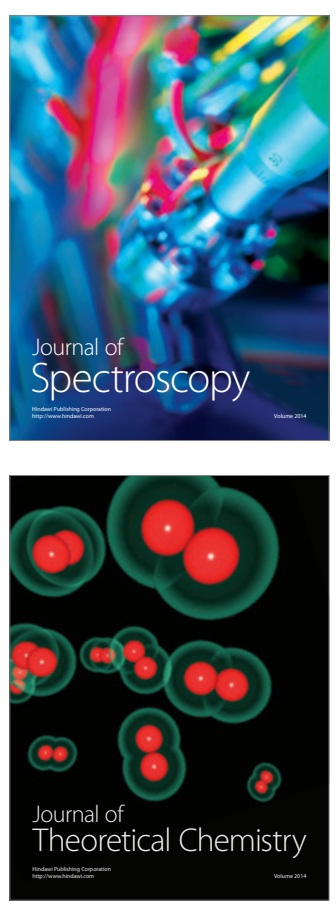
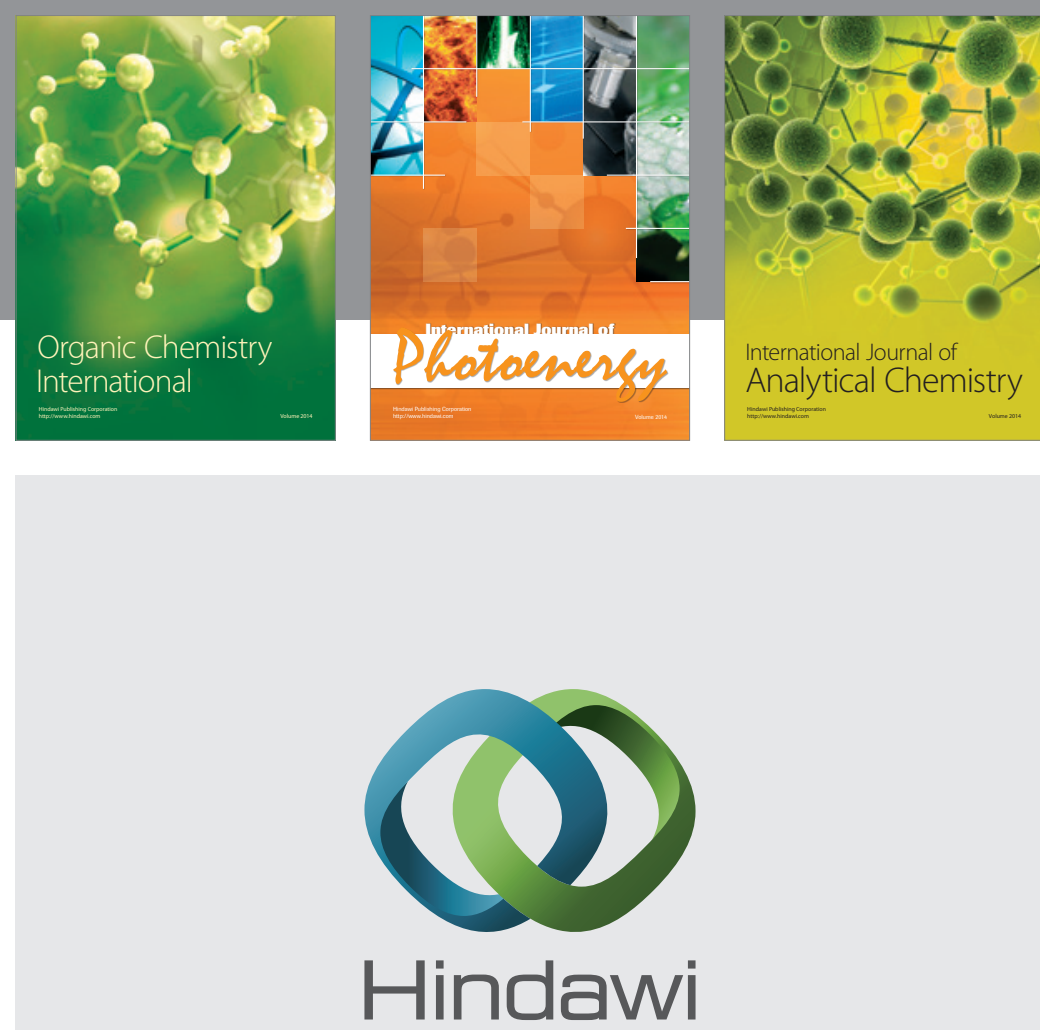

Submit your manuscripts at

http://www.hindawi.com
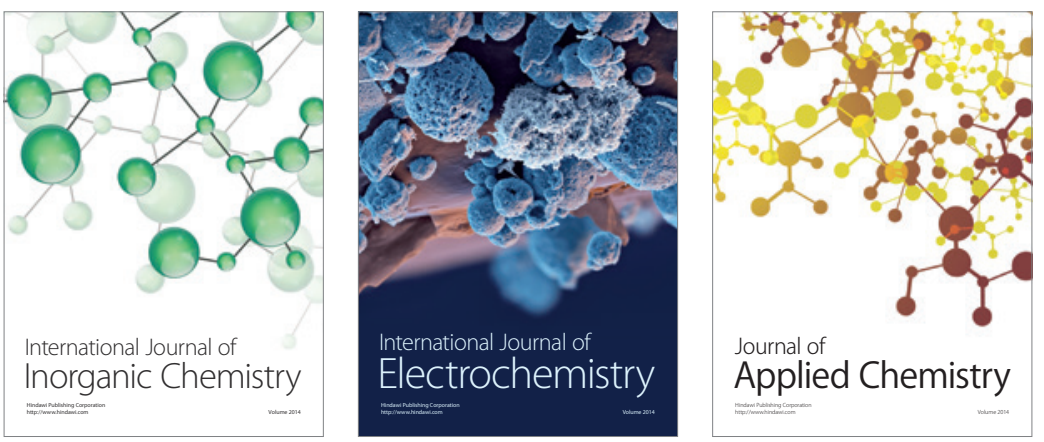

Journal of

Applied Chemistry
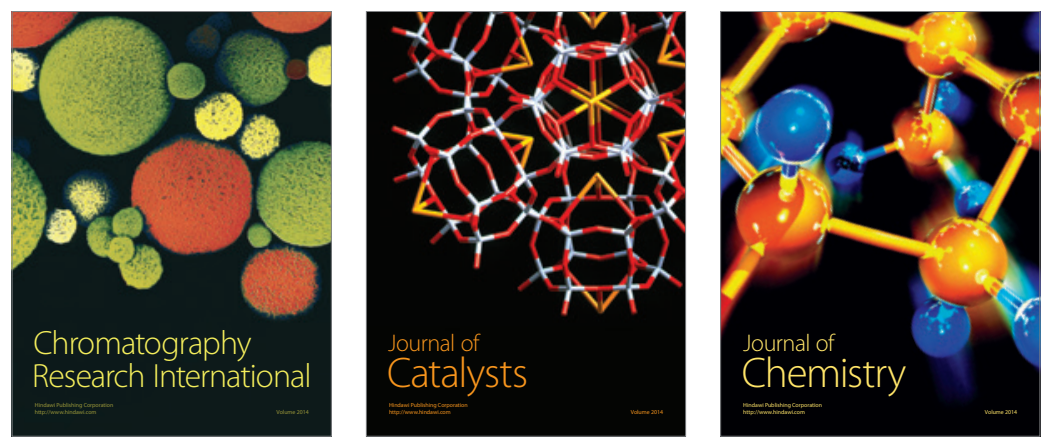
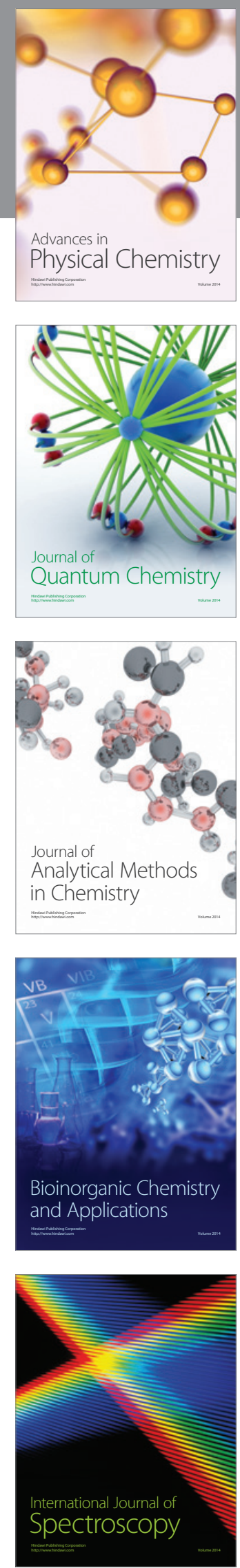